department. She was also the only woman in the department to receive tenure until her protégé, Christine Dunham, joined the tenure ranks in 2016. "I felt a commitment to help her along the way," Corbett says. "She was easy to mentor because she was so smart and driven."

Lots of lab leaders talk a good game when it comes to mentorship, but Corbett thinks that they don't always put in the necessary thought and effort. "Some who think they are good mentors are the worst," she says. "It's important to be purposeful. Sit down and think about what it really takes." Even with her long history of successful partnerships with colleagues and students, Corbett doesn't take her own skills for granted. Earlier this year, she attended a mentoring workshop conducted by the Howard Hughes Medical Institute in Chevy Chase, Maryland. "There's a growing realization that mentoring isn't something that we're trained to do," she says.

Corbett says that thoughtful mentoring can be particularly valuable - and personally rewarding - when one is working with students from ethnic or cultural backgrounds that are under-represented in the sciences. "You can see that they've got a ton of grit and persistence, but they don't necessarily have the resources and tools to succeed," she says. "There's nothing more exciting than seeing them continue on a trajectory toward success."

\section{COMMITMENT TO CARING}

After more than 40 years in various academic positions, Warner has felt that thrill many times over. "I want my students to succeed as much as I want my own kids to succeed," he says.

He is especially proud of students who make it despite humble beginnings. He often notes that neither of his parents graduated from high school, and that he himself went to an impoverished high school in Bunkie, Louisiana, a world away from East Coast college-preparatory schools.

His commitment to diversity shows: the LSU chemistry department consistently produces more African American PhD graduates than does any other chemistry department in the country.

Cole is grateful for her breakdown in Warner's office. "I think he saw then that I was ambitious," she says. "He probably figured that I would never fail again if given a second chance." From that time on, he pushed her hard and kept his expectations high.

She met those expectations, and then some. "She was one of the best people to ever come out of my group," Warner says. "But if she was in another group that didn't have that confidence in her, she might not have made it." -

Chris Woolston is a freelance writer in Billings, Montana.

\title{
COLUMN
}

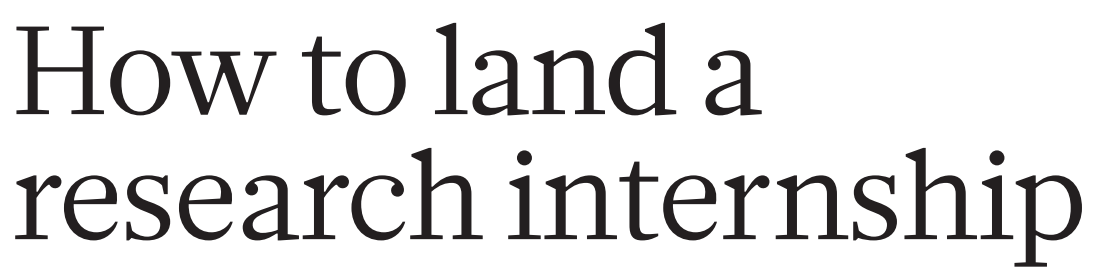

\section{Personalized recommendations and a solid science CV are crucial, say Ruth Gotian and Ushma S. Neill.}

$\mathrm{R}$ esearch-intensive internship programmes for undergraduates offered by medical and graduate schools are in high demand. Here, based on our 25 years of collective experience running these programmes in the United States, we outline what you need to win an internship.

\section{LETTERS OF RECOMMENDATION}

The worst ones focus on the faculty member's qualifications. Highlights of basic requirements, such as, "She submitted assignments on time, was punctual and participated in discussions", are not useful.

But enthusiasm radiates off the page when the recommender truly knows the student, in statements such as, "She is a joy to teach, and makes other students look like zombies." Get to know your recommender, so that they can comment on your tenacity and personality. Note that your letters - solicit at least two, but check programme requirements should come from faculty members, and not from postdocs or teaching assistants.

Also, consider the timing of your request. Asking for a recommendation while faculty members are grading exams or preparing to leave for holiday will not work well. Propose drafting parts of the letter, highlighting your skills and accomplishments. The faculty member might not know that you write for the university paper or have a part-time job. When you provide this information, they can focus on writing about your intellectual prowess and critical-thinking skills.

\section{PERSONAL STATEMENT}

This section, the cornerstone of your application, must demonstrate what is unique about you and that you're dedicated to research. Avoid personal anecdotes, especially those about family illnesses, when explaining your drive. If a grandparent's stroke kindled your inspiration to go into neuroscience, make sure to explain what research or training you've done since that event.

One of the other most common openings to these essays is the claim to enjoy solving puzzles - for example, "The brain is a perfect match for me because I love solving puzzles, and the brain is the ultimate

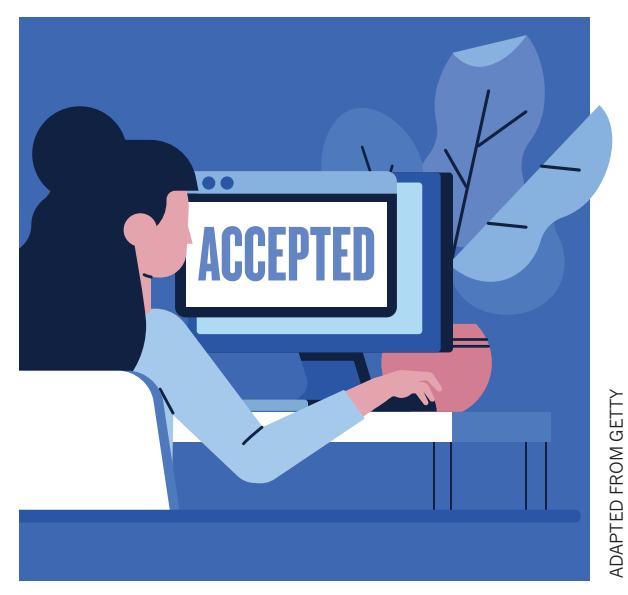

puzzle." Draw instead on what makes you unique.

Reviewers value applications that demonstrate the writer's previous research experience. But we know that not everyone has a great deal of this. If this is true for you, address it in your statement and emphasize your transferable skills, such as technological prowess or programming abilities. Finally, the personal statement is the place to explain your low mark in calculus or your short-term leave. Don't just hope that no one will notice.

\section{GRADES AND TRANSCRIPTS}

In a transcript review, where you went to school is not nearly as important as what you did while you were there. Make sure to take a balance of science, technology, engineering and mathematics (STEM) and non-STEM classes.

Applicants who distinguished themselves in their applications have turned out to be among the best interns we've hosted. We knew them by their names and their stories before they arrived. We took special care with them, and many of those mentoring relationships continue today.

Ruth Gotian is the assistant dean for mentoring and chieflearning officer in anaesthesiology at Weill Cornell Medicine in New York City. Ushma S. Neill is vice-president in the Office of Scientific Education and Training at the Memorial Sloan Kettering Cancer Center in New York City. 